\title{
Enhancing learning environments through partnerships in an attempt to facilitate school effectiveness
}

\author{
Tracey-Ann Adonis', Shaheed Hartley ${ }^{2}$ \\ ${ }^{1}$ Community Engagement Unit, Office of the Deputy Vice Chancellor (Academic), \\ University of the Western Cape, South Africa, ${ }^{2}$ Science Learning Centre for Africa, Faculty \\ of Education, University of the Western Cape, South Africa.
}

\begin{abstract}
South Africa (SA) is a developing country struggling to address educational transformation inherited from a previous apartheid regime and created by the current democratic government. Education is an area which is struggling within a SA context. Many schools in disadvantaged communities are faced with inadequate infrastructure and lack of resources yet the expectation is for schools to show evidence of effectiveness irrespective of these challenges. This context prompted an investigation into the development of the school learning environment utilising a participatory action research design at a disadvantaged primary school in the Western Cape, SA. The major findings included that the school learning environment was influenced by the unique challenges and pressures in the school context; that collaborative efforts between stakeholders contribute to school effectiveness irrespective of context through acknowledging the school as an organisational system which requires the principal, educators, parents and community to effectively collaborate through open channels of communication in order to facilitate optimal teaching and learning environments which contribute to school effectiveness. The community component in the school learning environment needed to be acknowledged as the validation of the experiences of educators, learners, parents, principal and community is important in the South African context.
\end{abstract}

Keywords: Education; school effectiveness; learning environments, partnership; collaboration. 


\section{Introduction}

Within the post 1994 South African (SA) context of change, education is regarded as one of South Africa's key problem areas (Oswald \& Perold, 2015, p.2). A report commissioned by the Centre for Development and Enterprise highlighted the South African Education Crisis and the quality of education in South Africa from 1994 - 2011. Some of the key findings from this report were that there was no improvement in South African Grade Six literacy or numeracy performance over the seven year period; South African pupils ranked 10th of the 14 education systems for reading and 8th for mathematics, behind much poorer countries such as Tanzania, Kenya and Swaziland; South African mathematics teachers have belowbasic levels of content knowledge; school data showed that of the 100 pupils that start grade one, 50 will drop-out before Grade 12 (most of which happens in grade 10 and 11), 40 will pass the National Senior Certificate (NSC) exam and 12 will qualify for university and that there is a distinct educational divide and effectively two different public school systems in South Africa (the smaller, better performing system accommodates the wealthiest 20-25 per cent of pupils who achieve much higher scores than the larger system which caters to the poorest 75-80 per cent of pupils) (Spaull, 2013, p. 4-7). This summary indicates that the state of education in South Africa is critical and if we really intend to develop the state of education we need to improve the socio-economic status for the majority of South Africans.

Nicolson (2015) reported that 12 million people in SA live in extreme poverty. The Organisation for Economic Co-operation and Development (OECD, 2017) has expanded on the severe economic threat that the poor state of education poses to this country which has a legacy of racial classification and hierarchy based on skin colour. This is particularly evident in the great degree of inequality between previously and still advantaged white schools that have a wealth of resources resultant from a historical background which favoured the white race as opposed to the previously and still disadvantaged black schools where resources are lacking. The challenge of facilitating effective learning environments in this context, given the socio-economic and sociological problems that are direct spin-offs of poverty such as unemployment and low levels of education of parents particularly in disadvantaged communities, places a huge responsibility on the shoulders of the managers and educators at schools. The latter argument is critical given the decentralisation of the state's role in schools post 1994 where partnerships with the community and stronger relationships with 'those closest to the learner' (preferably parents) are encouraged and in fact is a key principle in education reconstruction and legislated within a South African context (Heystek, 2011). Parents, guardians and caregivers of learners are therefore required to participate in the governance structure of the school and inherent in this policy requirement is that communities possess knowledge and resources. The reality though places a huge responsibility on principals and educators as disadvantaged communities are characterised by poverty, unemployment and low levels of education. The impact of poverty is such that parents of 
learners from poor schools often have low educational qualifications and have several needs that supercedes educational involvement such as health care and employment (Kamper, 2008, p.2).

Quality educational experiences are largely impacted by the resource capacity of parents in the South African reality. More often than not, parents are not equipped to deal with the complex nature of tasks and concepts particularly in science and mathematics. Singh, Mbokodi \& Msila (2004, p. 301) found that "presently, there appears to be insufficient participation of black parents in managing schools..." The reality of context, socio economics and social class is therefore largely ignored yet it plays an important role in the optimal involvement of the community in the school.

Overcrowded classrooms are unfortunately the norm within South African education and Marais (2016, p.1) asserts that it will 'remain a part for the immediate future and perhaps even for the long-term future.' Irrespective of the dire state of education within SA, 'the strategic importance of teachers cannot be denied as they are expected to act as agents of change and have a key role in ensuring that quality education is delivered to all children regardless of context' (Oswald \& Perold, 2015, p.2). The impact of overcrowded classrooms does not bode well for quality education and facilitating an ideal learning environment is extremely difficult and may contribute to a challenging learning environment which is not conducive to learning and essentially quality education (Marais, 2016). Developing innovative strategies to overcome barriers to educational success is critical within the South African educational landscape particularly as the aim is to deliver quality education and thus contribute to school effectiveness. Education is complex within the 21st century and therefore new perspectives are required that address how parents, schools, and communities will work together to face these challenges.

The theoretical framework for this study relies on systems thinking as this theory provides a holistic perspective of the world. Rooted in biology, the theory seeks to understand the school as a system, as an integrated whole found within a specific context where various shared environments overlap (Bronfenbrenner, 1979). Bronfenbrenner's (2005) ecological systems perspective is valuable as it recognises the school as a system and calls for a holistic understanding that educators and families are the most influential environment in children's learning and development within a complex set of 'layers'. The ecological model recognises the complexity of the individual's context of development (Mampane \& Huddle, 2017). The school can therefore be regarded as an ecological system that is dynamic and which is highly dependent upon connections, affiliations and communications between the system's components, in this case, the principal, educators, parents and learners.

Learning environments therefore need to be investigated within the holistic systems view of the school. This study provided educators, parents, principal and the education department 
with an opportunity to contribute to a process of transformation and change in their specific context. The implications of this study therefore delivered an exemplar of a historically disadvantaged school engaging in a participatory action research study with the aim to be effective. The research question for this study was 'What is the nature of the learning environment at a primary school in a sub-economic community with regard to the key role players at the school (principal, educators and parents) and how do these collaborations influence the school learning environment and essentially impact on school effectiveness?'

\section{Methodology}

A community based participatory action research approach was implemented as it emphasised social action and possibly would facilitate my vision to plough back. The rationale for community based PAR draws on diverse historical influences and is guided by the following principles:

a) It is a collaborative enterprise between the academic researcher and community members which in this case are the principals, teachers, parents and learners. Facilitating a collaborative process is essential as rapport building and establishing trust between the community members is essential as we attempt to facilitate optimal data collection.

b) It validates multiple sources of knowledge and promotes the use of multiple methods of discovery and dissemination of the knowledge that could be produced. The use of this research approach would therefore facilitate that research instruments need to be thoughtfully selected and developed in order to ensure that the data collected characterizes the indigenous knowledge present within the primary school communities.

c) It has as its goal social action and social change for the purpose of achieving social justice.

This research was an intensive exploration of the school learning environment at a primary school over a period of four years. At the time that the research commenced (2014), the principal had just been appointed and had a staff of eleven educators and two non-teaching posts. These numbers have subsequently increased to a teaching staff of twenty and five nonteaching posts by 2016. In 2014 there were 400 learners at the school and in 2017 these numbers increased to 706 .

Multiple sources of data were used in the research process as the researcher aimed to capture the importance of contextual detail and in-depth description (Babbie \& Mouton, 2006). Quantitative and qualitative data collection tools were utilised in this study which enabled the researcher to explore the rich context while recognizing that multiple sources of evidence 
(survey, field-notes, interview comments and digital recordings) will increase convergence of results so that results were triangulated which also contributed to the reliability of the research.

The following chronological steps were followed in the data collection phase of the research:

Step 1: Gathering baseline information at the school regarding the educators' and principal's views of how they experience the actual learning environment vs how they would prefer the learning environment to look like and identify trends.

Step 2: Conducting interviews with key stakeholders (educators, principal and parents) as they work towards facilitating school effectiveness. Critically analyzing these findings.

Step 3: Developing interventions in response to the priority needs identified from step 1 and 2 which included the following activities:

1. Developing a collectively owned mission and vision statement.

2. Supporting parents to understand the CAPS curriculum to assist their children and struggling learners in the school

3. Science laboratory

Step 4: Evaluation of interventions

\section{Major findings}

\subsection{The school learning environment was influenced by the school context}

The school learning environment cannot be viewed in isolation within a community and the context of historically disadvantaged communities needed to be recognised and was therefore important. Policy level curriculum reforms which educators were expected to implement, resulted in work pressure due to a lack of resources in the disadvantaged context, the latter was perceived to contribute to ineffective teaching and learning.

\subsection{Collaborative efforts with all stakeholders contribute to school effectiveness}

There were different levels of collaboration within this school's context. These collaborative efforts were perceived to contribute to school effectiveness however the different levels of collaboration could be enhanced through appropriate capacity building for stakeholders. The need for effective channels of communication was highlighted which would facilitate partnership development. The role of the parents in this school was to contribute to the development of the learning environment through effective participation in their child/ren's education through engaging in regular communication and feedback with educators. The parent body identified a need for an effective communication strategy that seeks to increase their involvement in the school which extends beyond the immediate parent-learner-educator 
interaction to parent committees and an active school governing body. Parents need to understand their specific role as it relates to the policy and realise that their involvement is critical to the contribution that the school makes to the community.

\subsection{The school as an organisational system was recognised in the development of a collectively owned mission statement}

The school needed to be regarded as an organisational system where the interaction, collaboration and partnership between each stakeholder, namely the educators, principal, parents, learners and the community, were central to facilitating school effectiveness. The role of the principal is critical in this system as his leadership employed a distributive / transformational leadership and management approach within the school setting. Organisational development skills were perceived by educators to be valuable and contributed to the learning environment as it provided educators with the opportunity to engage in collaborative, creative thinking processes and collective decision-making.

\subsection{The interventions provided much needed resources which facilitated effective teaching and learning}

The educators recognised that the collective and collaborative strategic session generated a mission and vision statement that provided the educators with the necessary guidance in the school learning environment and an initial means for quality assurance in their educational setting. The fact that only educators and the principal were involved in the development of the mission and vision was acknowledged and a subsequent review of the mission and vision is planned where parents' input will also be required.

The reading and writing volunteers provide a human resource for the school and function as a support role for educators who are unable to provide struggling leaners with increased individual contact time.

Another major outcome of this research was the science learning centre which was built at the school and represented possibility for the stakeholders as it was perceived to enhance the teaching and learning at the school. The role of the education department would be to acknowledge the school as an exemplar of a community school that explores and facilitated the development of innovative, collaborative partnerships with a higher education institution, principal, educators, parents, and the surrounding community as it seeks to be an effective school and produce successful learners, irrespective of its historically disadvantaged context.

\section{Conclusion}

An exploration of the unique learning environment context of primary schools and the value that collaborations between the principals, educators and parents added to the classroom 
learning environment was valuable in the sense that this knowledge contributed to a unique set of lessons learnt that could be applied to other learning environments thus laying the foundation for the effectiveness of schools.

The study was significant as it provided an exemplar of the developmental aspect of facilitating 'ideal' learning environments through partnerships between principals, teachers and parents and the community at primary school level in a disadvantaged community. This study furthermore contributed to the knowledge of collaborative enterprises and learning environments; specifically within disadvantaged schools. This study provided unique baseline information on partnerships at the primary school level and the intricate balances and support provided at each level of partnership as it aims to improve learning environments and facilitate school effectiveness. External influence and collaborative efforts conducted and implemented in partnership with the school, contribute to educational effectiveness and could possibly influence educational transformation.

\section{References}

Babbie, E., \& Mouton, J. (2006).The practice of social research 6th edition. Cape Town: Oxford University Press.

Heystek, J. (2011). School Governing Bodies in South African Schools: Under Pressure to Enhance Democratisation and Improve Quality. Educational Management Administration \& Leadership, 39(4), 455 - 468.

Kamper, G. 2008. A profile of effective leadership in some South African high-poverty schools. South African Journal of Education, 28, 1-18. (C) 2008 EASA

Mafora, P. (2013). Learners' and teachers' perceptions of principals' leadership in Soweto secondary schools: a social justice analysis. South African Journal of Education, 33(3). Art\#621, 15 pages, http://www.sajournalofeducation.co.za

Mampane, R. \& Huddle, C. (2017). Assessing the outcomes of school-based partnership resilience intervention. South African Journal of Education, 37(1), February. http://doi.10.15700/saje.v37na1412

Marais, P. (2016). “we can’t believe what we see’: Overcrowded classrooms through the eyes of student teachers. South African Journal of Education, 36(2), 1-10, May 2016. Retrieved from http://www.sajournalofeducation.co.za

Nicolson, G. (2015, January 30). South Africa: Where 12 million live in extreme poverty. https://www.dailymaverick.co.za/article/2015-02-03-south-africa-where-12-millionlive-in-extreme-poverty/\#.WI-HB00aKUk

Organisation for Economic Co-operation and Development (OECD). (2017). Economic Surveys South Africa 2017 Overview. Retrieved from http://www.oecd.org/eco/surveys/economic-survey-southafrica.htm 
Oswald, M. \& Perold, O. (2015). A teacher's identity trajectory within a context of change. South African Journal of Education, 35(1). February 2015. Retrieved from http://www.sajournalofeducation.co.za

Singh, P., Mbokodi, S.M. \& Msila, V.T. (2004). Black parental involvement in education. South African Journal of Education, 24(4), 301-307.

South Africa Department of Education. (1998). National norms and standards for school funding in terms of the South African Schools Act, 1996 (Act No. 84, 1996). [Online] Available: http://www.polity.org.za/govdocs/policy/norms\&standards.html

Southern and Eastern Consortium for Monitoring and Educational Quality (SACMEQ). (2015). SACMEQ Project 2005-2010. Retrieved from http://microdata.worldbank.org/index.php/catalog/1246/overview

Spaull, N. (2013). South Africa's Education Crisis: The quality of education in South Africa 1994 - 2011. Report Commissioned by the Centre for Development \& Enterprise (CDE). Available at http://www.section27.org.za/wp-content/uploads/2013/10/Spaull-2013CDE-report-South-Africas-Education-Crisis.pdf. Accessed 10 May 2017.

Statistics South Africa. (2010). Mid-year population estimate, statistical release, P0302. Retrieved from http://www.statssa.gov.za/census01/html/RSAPrimary.pdf 